\title{
The Development of Hypnotherapy Based - Interpersonal Communication Model For Students Suffered From Game Addiction
}

\author{
Imma Rachayu ${ }^{1}$, Azizatul Banat ${ }^{2}$ \\ ${ }^{1}$ Computer Education, Universitas Dehasen Bengkulu, Indonesia \\ Email: immarachayu@ unived.ac.id \\ ${ }^{2}$ Physical Education, Universitas Dehasen Bengkulu, Indonesia \\ Email: azizatulbanat@unived.ac.id
}

\begin{abstract}
(Received: October-2019; Reviewed: December-2019; Accepted: February-2020; Available online: February 2020; Published: April-2020)
\end{abstract}

\begin{abstract}
The purpose of this study is to produce a hypnotherapy-based interpersonal communication model for students who have contracted online games to improve the students' academic achievement at PTIK Dehasen University Bengkulu. The research method was used in development research with limited trials. The results of this limited trial, had aspects determined to state that the hypnotherapy-based interpersonal communication model developed is effective, efficient and practical have been fulfilled, then the development cycle to get an effective, efficient and practical therapy model has ended. This study can be concluded that the hypnotherapy-based communication model is able to reduce the level of online game addiction gradually and consistently, and can influence students' attitudes, opinions and behavior in a dialogic manner and have a positive impact of mental relaxation and a continuous learning spirit so that student academic achievement can increase significantly.
\end{abstract}

Keywords: communication, interpersonal, hypnotherapy, online game, achievement.

\section{INTRODUCTION}

World Health Organization (WHO) is to state game addiction as one of the mental problems. Based on the $11^{\text {th }}$ Revision of the International Classification of Diseases (ICD), this problem is referred to as gaming disorder. WHO describes it as to play games persistently and continuously thus ignoring other important activities (Billieux et al., 2017; Király \& Demetrovics, 2017; Saunders et al., 2017). Some criteria of this addiction include salience, tolerance, mood modification, relapse, withdrawal, conflict, and problems (Griffiths, 2010; Monacis, De Palo, Griffiths, \& Sinatra, 2016).

Indonesia has become a massive market as it has 250 million population. It is the fourth biggest populated country (after China, India, and the USA). Therefore, even only $1 \%$ of its population suffered from game addiction, it is regarded as a very big number. A study carried out by the Newzoo-consumer research group indicated that in 2017, Indonesia was in the $16^{\text {th }}$ rank, while in 2015 it was still in the $24^{\text {th }}$ rank. (Newzoo, 2017).

There have been a number of studies evaluating various methods to solve the addiction of games. One of them tested Bupropian to 19 males suffered from the disorder. It was successful to reduce their addiction level but the result highly depended on the personality of each subject (Han, Hwang, \& Renshaw, 2010). Furthermore, the family therapy interference model can also decrease the game addiction on teenagers under 15 years old 
(Han, Kim, Lee, \& Renshaw, 2012). Cognitive Behavioral Therapy (CBT) method was used to minimize the addiction of game online on 16 year old boys (King, Delfabbro, Griffiths, \& Gradisar, 2012). The combination between Cognitive Behavioral Therapy (CBT) and Bupropian has been proven to minimize the game addiction on 65 respondents (17 years old) (Kim, Han, Lee, \& Renshaw, 2012). However, none of those studies combined hypnotherapy based interpersonal communication to eradicate the game addiction.

Basically, interpersonal communication is a self-concept that can affect the communication due to the ability to receive the message delivered through the communication. More importantly, there is willingness to communicate well (De Choudhury, Mason, Hofman, \& Watts, 2010; Kwon, Chung, \& Lee, 2011; Li \& Wang, 2013). While hypnotherapy is a model that can be used to change human's behavior which focusing on their subconscious mind (Albery \& Munafo, 2011). This is in line with the study carried out by Wulandari, Hamid, \& Ridfa (2016) showing that the method can reduce the smoking intensity on teenagers.

There have been various hypnotherapy based interpersonal communication models developed which aim to reduce the addictive level of online game on teenagers.

\section{METHOD}

This research employed the developmental design method introduced by Sugiyono (2016) which consists of planning, organizing, implementing, evaluating, and reporting.

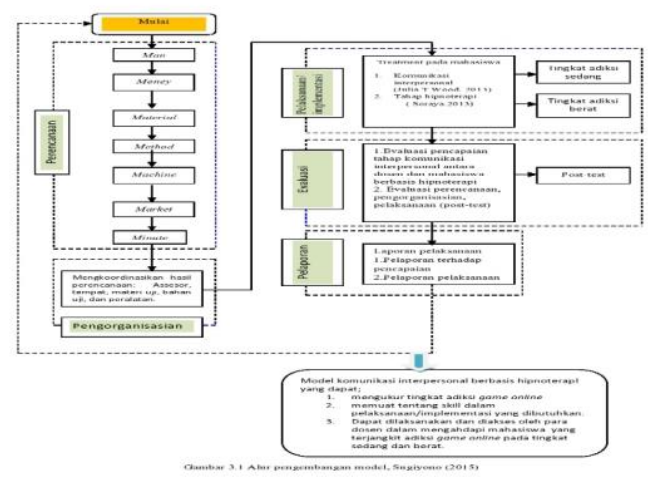

Figure 1. Developmental Model (Sugiyono, 2017)
We validated the research instruments to ensure their practicality and effectiveness so that the hypnotherapy based interpersonal communication model that we developed can be accounted for. Therefore, in this study, we had to carry out pre-survey, pre-trial and field trial and to implement the instruments which have been developed based on Sugiyono (2017).

This study involved 13 PTIK students at Dehasen Bengkulu University in the academic year of 2018/2019 aged between 18 and 22. The data related with research focus were grouped into two categories: medium and hard game addictions.

The instrument utilized in the study was a questionnaire developed by referring to client addiction criteria by Lemmens, Valkenburg, \& Peter (2009). Some criteria of online game addiction are salience (the client is thinking to play a game all day), tolerance (duration spent by client to play a game is increasing), mood modification (the client plays a game and ignores other activities), relapse (the client has a tendency to back to the game after long time not playing it), withdrawal (the client feels bad when unable to play the game), conflict (the client contends with other people after too much playing) and problems (since the client tends to ignore other important activities, he/she will end up with new problems). This questionnaire has been validated by a field observer team consisting of person with the profession as senior hypnotherapists (certified hypnotherapist).

Data were collected by testing all 13 students from Information Technology and Communication Education Program, Dehasen University. Following that, they were intervened with 45-minute therapy. Then, they were analyzed based on addiction rate reports obtained after giving the hypnotherapy.

The data were analyzed by studying the potential and problems existing in the research object and the identity of objects which were being developed. They were then designed and determined based on the specification of products and analysed descriptively and quantitatively. Following that, the results were analysed limited on factual aspects as revision of products. Next, we carried out a statistical calculation which was in line with the proposed problems and products which were being developed. Lastly, the report was designed and adjusted with the needs of potential consumers or users. 


\section{RESULTS AND DISCUSSION}

\section{Results}

This is a developmental study that aimed to develop a therapy syntax that can be used by students who are suffered from game addiction.

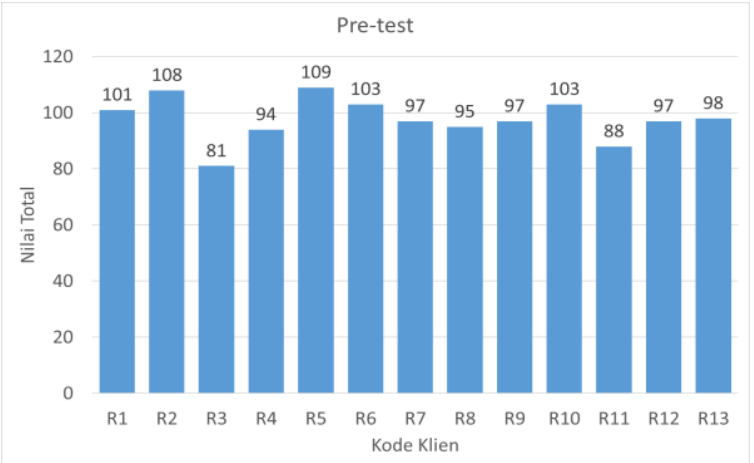

Figure 2. Results of pre-test of online game addiction level of 13 clients.

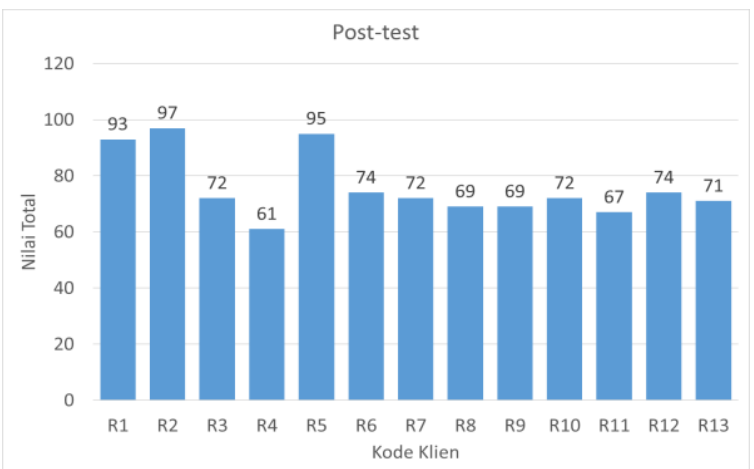

Figure 3. Results of posttest of online game addiction level of 13 clients.

The categorization indicates that the clients experienced low, medium and high addiction when they were in the range of $0-37$, 38-74, and 75-111 respectively. The pretest of online game addiction level indicated that all 13 clients were in the high category. This data can be seen in Figure 1. After giving a post-test, the results of the test given to 13 clients are presented in Figure 2.

The results of the pretest showed that 30 questions with scales of 1-4 describe the criteria of clients with online game addiction (Lemmens, Valkenburg, \& Gentile, 2015). The game addiction criteria are shown in Figure 4.

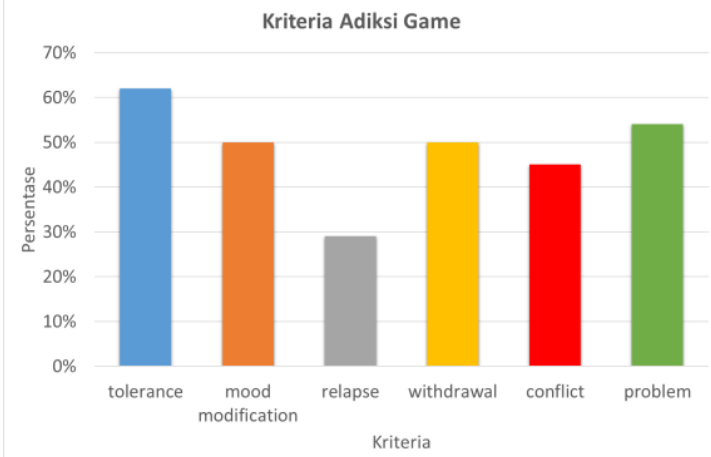

Figure 4. Results of the test of game addiction criteria of 13 clients.

Data referring to salience are represented by clients' statements about their contentment on online game, whether their duration in playing online game $\geq 2$ hours in a day, whether they totally understand about the ins and outs of the game, whether they are willing to queue and set aside their allowance to play the game, about their curiosity level to complete the levels in online game, and whether they feel uneasy not having money to buy internet data. Based on this statement, $62 \%$ of clients were on the scale of 4 .

The aspect of tolerance which indicates the points that the clients forgot to do the lecture assignments, the clients joined the online gaming community, and the clients played online games every day until late at night or until dawn, was at a scale of 4 by $50 \%$ of respondents.

The mood modification is stated in the statements that the clients collect college assignments on time, the clients are less likely to visit their relatives, and the clients are willing to skip their meal. $29 \%$ of respondents gave the 'always' statement or showed the highest scale (4).

The relapse condition is represented by the clients' idolization of the characters in the online game, the tendency of the clients to repeat the same game even though they have already completed it, the encouragement experienced by the clients to complete other jobs so that they can immediately play online games, the boredom experienced by the clients if they do not play the game for 3 days, and the clients longs for an online game when they are sick. $50 \%$ of respondents are on a scale of 4 in this aspect.

The withdrawal aspect is expressed through statements about how disappointed they are if they lose the game, how angry they are if 
they are interrupted while playing online games, how often they vent their frustration if the lecture task interferes with online gameplay schedules, and how strong is their preference to make friends with people who also like online games. The results of data analysis showed that $45 \%$ of respondents were on a scale of 4 .

The conflict aspect is illustrated through information about how often the client is sleepy or asleep in class because of playing games late into the night until dawn, how high the frequency of clients willing to fight with parents or relatives if they prohibit clients from playing online games, and how often clients are willing to lie to lecturers or parents for the sake of playing online games. Data indicated that more than half of the clients (54\%) answered scale 3.

Finally, the problem aspect is illustrated by information about how often clients are called by academic supervisors because of their low attendance at lectures, how many times the client got an exam score below the competency standard, and how often they are kept quiet or angry by their parents for not being able to leave the game online. Data from the questionnaire showed that almost half the total clients (42\%) gave answers on a scale of 3 .

\section{Discussion}

This developmental study can provide therapy syntax to be used by students suffered from game addiction. Based on 4 addiction criteria, the tolerance aspect got the highest score as 13 clients chose the scale 4. Factors leading to the improvement of game addiction include therapeutical aspects, psychological problems, and demographical variables (Lee \& Jeong, 2015). Relapse criteria that refer to addiction indicators and the tendency to repeat to play similar games got a percentage of $29 \%$. The tendency to like something or a target spontaneously does not require a deep assessment but if the level of preference on the assessed or targeted aspect is high then it needs a very in-depth assessment (Ruys \& Stapel, 2009).

Based on a series of hypnotherapy activities performed to clients suffered from game addiction, we got developmental syntax of hypnotherapy based communication model that it is able to suggest them to increase their focal point in concentrating on moving their subconscious mind with the aim of reducing their desire to perform the addictive activities (Ajinkya, Jadhav, \& Ajinkya, 2015).

Based on figures 2 and 3, we know that there was a reduction in game addiction levels shown by the difference score between pre-test and post-test which is more specifically presented in figure 4 . The data shows a significant decrease in addiction experienced by 13 students aged between 18-22 with an average score of $22,42 \%$. The findings are in line with an earlier study investigating the benefits of hypnotherapy to reduce the addiction to illegal drugs experienced by 500 people. $70 \%$ of them were at the ages of 19-24 and the rests were between 13-18 years old and above 25. The treatment was given by suggesting patients concentrate on attention given to them. It was combined with cognitive techniques that aimed to change and transform their addiction. These research findings show that after giving the treatment for one to three months, $60-65 \%$ cases of illegal drug addiction were cured and the level of patients' withdrawal on this method after receiving therapy for a month (8-10 hours) was $20 \%$ (Grebnev, 2015).

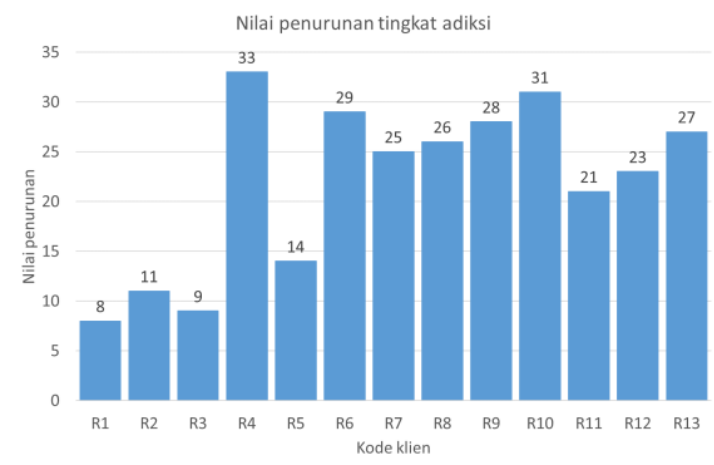

Figure 5. The reduction of game addiction levels experienced by 13 clients.

Hypnotherapy has been also proven to reduce headaches. Ahmadi et al (2018) treated $69,2 \%$ of subjects experiencing severe headaches and $30,8 \%$ with a moderate headache. After performing the hypnotherapy, the proportion of people with severe headache reduced to $7,7 \%$. The rate of patients having their severe headache reduced to moderate level was $45,5 \%$ while from moderate to mild was $54,5 \%$. This information indicated that hypnotherapy can become an effective cure therapy (Ahmadi et al., 2018).

Wilcoxon's statistical test with SPSS 21 showed the sign. value of 0.001 leading to the conclusion that there was a difference in addiction level before and after the intervention 
of hypnotherapy based interpersonal communication. This study is in line with Wulandari (2016) that hypnotheraphy reduces the teenagers' smoking intensity $(\mathrm{p}=0,001)$. While research carried out by Martingningtyas (2012) found that (1) Hypnotherapy can reduce the stress level of psychosomatic gastritis sufferers. All participants had their stress level minimized fairly consistently in each stage; (2) Participants who achieved optimal stress reduction success were participant 1 and participant 2 . This indicates that hypnotherapy is more effective to patients with psychosomatic gastritis with high levels of stress in the high category; (3) Every participant got new positive habits. Participants 1 and 2 became accustomed to self-hypnosis to find calm and relaxation for their bodies. While participant 3 became more often prejudiced or to think positively to maintain the mood to stay excited in carrying out their activities. These results are also supported by research conducted at North Shore Medical Center, Salem, Massachusetts between October 2006 and May 2009, with the aim of reducing addiction to smoking using hypnotherapy that involved 39 patients. The conclusion is that after 12 weeks of therapy, $43.9 \%$ of patients stopped smoking. (Hasan et al., 2014).

Aspects determining whether the hypnotherapy-based interpersonal communication model developed in the research effective, efficient and practical have been fulfilled, then the development cycle has been considered complete. Although in this study all the criteria were met, researchers still made several revisions to get the final prototype. Revisions made include the use of language in the model book and questionnaire sheet. After the revision, a final prototype was obtained which in this case was a development model of interpersonal communication based on hypnotherapy that was effective, efficient and practical.

\section{CONCLUSIONS AND SUGGESTIONS}

Based on findings and discussion, it can be concluded that the hypnotherapy based communication model can reduce the online game addiction level and can influence the students' behavior, idea, and attitude dialogically. It also brings relaxation for positive thinking and motivates them to study continuously to significantly improve their academic achievement. Based on the results of the limited trial that has been carried out, the hypnotherapy based interpersonal communication model can effectively, efficiently, and practically reduce the students' online game addiction level.

Students should hypnotize themselves based on various indications they experience so that they can directly feel the impact. Furthermore, lecturers can utilize this hypnotic technique to suggest their students think and act more actively and concretely.

\section{REFERENCES}

Ahmadi, A. M., Jafari, M., Sabzevari, L., FallahTafti, A., \& Bidaki, R. (2018). Evaluation of the effect of hypnotherapy on the headache. Sleep and Hypnosis, 20(2), 114-119. https://doi.org/10.5350/Sleep.Hypn.2017.1 9.0142

Ajinkya, S., Jadhav, P., \& Ajinkya, D. (2015). Mindfulness-based hypnotherapy for common psychological disorders. European Journal of Psychology and Educational Studies, 2(1), 3. https://doi.org/10.4103/2395-2555.161414

Albery, I. P., \& Munafo, M. (2011). Psikologi Kesehatan, Panduan Lengkap dan Komprehensif Bagi Studi Psikologi Kesehatan. Mitra Setia.

Billieux, J., King, D. L., Higuchi, S., Achab, S., Bowden-Jones, H., Hao, W., ... Poznyak, V. (2017). Functional impairment matters in the screening and diagnosis of gaming disorder. Journal of Behavioral Addictions, 6(3), 285-289. https://doi.org/10.1556/2006.6.2017.036

De Choudhury, M., Mason, W. A., Hofman, J. M., \& Watts, D. J. (2010). Inferring relevant social networks from interpersonal communication. Proceedings of the 19th International Conference on World Wide Web, $\quad W W W$ '10, 301-310. https://doi.org/10.1145/1772690.1772722

Grebnev, S. A. (2015). Drug addiction. A new psychotherapeutic approach. 1(8), 87-93.

Griffiths, M. D. (2010). The role of context in online gaming excess and addiction: Some case study evidence. International Journal of Mental Health and Addiction, 8(1), 119125. https://doi.org/10.1007/s11469-0099229-x 
Han, D. H., Hwang, J. W., \& Renshaw, P. F. (2010). Bupropion sustained release treatment decreases craving for video games and cue-induced brain activity in patients with internet video game addiction. Experimental and Clinical Psychopharmacology, 18(4), 297-304. https://doi.org/10.1037/a0020023

Han, D. H., Kim, S. M., Lee, Y. S., \& Renshaw, P. F. (2012). The effect of family therapy on the changes in the severity of on-line game play and brain activity in adolescents with on-line game addiction. Psychiatry Research - Neuroimaging, 202(2), 126131.

https://doi.org/10.1016/j.pscychresns.2012. 02.011

Hasan, F. M., Zagarins, S. E., Pischke, K. M., Saiyed, S., Bettencourt, A. M., Beal, L., ... McCleary, N. (2014). Hypnotherapy is more effective than nicotine replacement therapy for smoking cessation: Results of a randomized controlled trial. Complementary Therapies in Medicine, 22(1), $1-8$. https://doi.org/10.1016/j.ctim.2013.12.012

Kim, S. M., Han, D. H., Lee, Y. S., \& Renshaw, P. F. (2012). Combined cognitive behavioral therapy and bupropion for the treatment of problematic on-line game play in adolescents with major depressive disorder. Computers in Human Behavior, 28(5), 1954-1959. https://doi.org/10.1016/j.chb.2012.05.015

King, D. L., Delfabbro, P. H., Griffiths, M. D., \& Gradisar, M. (2012). CognitiveBehavioral Approaches to Outpatient Treatment of Internet Addiction in Children and Adolescents. Journal of Clinical Psychology, 68(11), 1185-1195. https://doi.org/10.1002/jclp.21918

Király, O., \& Demetrovics, Z. (2017). Inclusion of gaming disorder in ICD has more advantages than disadvantages. Journal of Behavioral Addictions, 6(3), 280-284. https://doi.org/10.1556/2006.6.2017.046

Kwon, J. H., Chung, C. S., \& Lee, J. (2011). The effects of escape from self and interpersonal relationship on the pathological use of internet games. Community Mental Health Journal, 47(1), 113-121. https://doi.org/10.1007/s10597-
009-9236-1

Lee, H. R., \& Jeong, E. J. (2015). Psychological Needs of Game Addiction: An Exploratory Study Focusing on Therapeutic Catharsis Seeking and Game Self-Efficacy. Journal of Korea Game Society, 15(3), 123-134. https://doi.org/10.7583/jkgs.2015.15.3.123

Lemmens, J. S., Valkenburg, P. M., \& Gentile, D. A. (2015). The internet gaming disorder scale. Psychological Assessment, 27(2), 567-582.

https://doi.org/10.1037/pas0000062

Lemmens, J. S., Valkenburg, P. M., \& Peter, J. (2009). Development and validation of a game addiction scale for adolescents. Media Psychology, 12(1), 77-95. https://doi.org/10.1080/152132608026694 58

Li, H., \& Wang, S. (2013). The role of cognitive distortion in online game addiction among Chinese adolescents. Children and Youth Services Review, 35(9), 1468-1475. https://doi.org/10.1016/j.childyouth.2013.0 5.021

Monacis, L., De Palo, V., Griffiths, M. D., \& Sinatra, M. (2016). Validation of the Internet Gaming Disorder Scale - ShortForm (IGDS9-SF) in an Italian-speaking sample. Journal of Behavioral Addictions, 5(4), 683-690. https://doi.org/10.1556/2006.5.2016.083

Ruys, K. I., \& Stapel, D. A. (2009). Learning to like or dislike by association: No need for contingency awareness. Journal of Experimental Social Psychology, 45(6), 1277-1280. https://doi.org/10.1016/j.jesp.2009.06.012

Saunders, J. B., Hao, W., Long, J., King, D. L., Mann, K., Fauth-Bühler, M., ... Poznyak, V. (2017). Gaming disorder: Its delineation as an important condition for diagnosis, management, and prevention. Journal of Behavioral Addictions, 6(3), 271-279. https://doi.org/10.1556/2006.6.2017.039

Sugiyono, M. P. K. (2016). Metode Penelitian dan Pengembangan Research and Development, CV. Alfabeta, Bandung.

Wulandari, A., Hamid, H., \& Ridfa, A. (2016). Pengaruh hipnoterapi terhadap penurunan intensitas merokok pada remaja. Skripsi. Makassar. Universitas Negeri Makassar. 